\section{Kidney \\ Blood Pressure \\ Research}

Kidney Blood Press Res 2012;36:231-241

\begin{tabular}{l|l}
\hline DOI: $10.1159 / 000343412$ & C 2012 S. Karger AG, Basel
\end{tabular}

www.karger.com $/ \mathrm{kbr}$

231

Original Paper

\title{
Associations of Proteinuria, Fluid Volume Imbalance, and Body Mass Index with Circadian Ambulatory Blood Pressure in Chronic Kidney Disease Patients
}

\author{
Yasushi Ohashi Takatoshi Otani Reibin Tai Takayuki Okada Kentarou Tanaka \\ Yoshihide Tanaka Ken Sakai Atsushi Aikawa \\ Department of Nephrology, Toho University School of Medicine, Tokyo, Japan
}

\section{Key Words}

Ambulatory blood pressure monitoring Body composition - Bioelectrical impedance $\cdot$ Fluid balance $\cdot$ Chronic kidney disease

\begin{abstract}
Background/Aims: Obesity and hypervolemic status are the main causes of hypertension in patients with chronic kidney disease (CKD). However, it is difficult to differentiate between them. We aimed to assess the associations of body mass index (BMI) and total body water (TBW) with ambulatory blood pressure (ABP). Methods: Body composition by bioelectrical impedance analysis (BIA) and 24-h ABP were measured in 40 patients with CKD. TBW was assessed using corrected $\mathrm{TBW}_{\text {BIA }}$ adjusted for body surface area $\left(\mathrm{CTBW}_{\mathrm{BIA}}\right)$ and the $\mathrm{TBW}_{\mathrm{BIA}} /$ $\mathrm{TBW}_{\text {Watson }}$ ratio obtained using an anthropometric formula (Watson). Results: Elevated ABP (average 24-h BP $\geq 135 / 85 \mathrm{mmHg}$ ) was noted in 23 patients, who were more likely to have a higher $\mathrm{CTBW}_{\text {BIA }}$ and $\mathrm{TBW}_{\mathrm{BIA}} / \mathrm{TBW}_{\text {Watson }}$ ratio than patients without elevated BP. Patients with nocturnal non-dipping ( $<10 \%$ drop in $B P$ during sleep) were more likely to have a higher $\mathrm{TBW}_{\mathrm{BIA}} / \mathrm{TBW}_{\text {Watson }}$ ratio. Proteinuria and the $\mathrm{TBW}_{\mathrm{BIA}} / \mathrm{TBW}_{\text {Watson }}$ ratio were significant independent factors for 24-h ABP. BMI had a positive correlation with the $\mathrm{CTBW}_{\mathrm{BIA}^{\prime}} \mathrm{TBW}_{\mathrm{BIA}} / \mathrm{TBW}_{\text {watson }}$ ratio and furosemide use. Conclusion: Hypertension is dependent on proteinuria and fluid volume imbalance. The $\mathrm{TBW}_{\mathrm{BIA}} / \mathrm{TBW}_{\text {Watson }}$ ratio can serve as an indicator of fluid volume-dependent hypertension. BMI is affected by TBW, in which case BMI can become less involved with 24-h ABP.
\end{abstract}




\section{Kidney \\ Blood Pressure Research}

Kidney Blood Press Res 2012;36:231-241

\begin{tabular}{l|l}
\hline DOI: $10.1159 / 000343412$ & C) 2012 S. Karger AG, Basel \\
www.karger.com/kbr
\end{tabular}

Published online: November 19, 2012

Ohashi/Otani/Tai et al.: Circadian BP and Body Composition in CKD

\section{Introduction}

Hypertension occurs in approximately $80-85 \%$ of patients with chronic kidney disease (CKD) [1]. Hypertension in CKD results from excess fluid volume with sodium retention, increased renin-angiotensin activity, enhanced sympathetic nervous activity [2], secondary hyperparathyroidism [3], erythropoietin treatment [4], impaired nitric oxide synthesis [5], and endothelium-mediated vasodilatation [5]. Lastly, hypertension itself causes or contributes to the development of CKD [6]. Moreover, patients with CKD may not demonstrate the normal nocturnal decline in blood pressure (BP), and are consequently at possible risk of hypertensive complications [7]. In the general population, body mass index (BMI) is closely associated with hypertension, which promotes atherosclerotic cardiovascular disease (CVD) and is associated with increased mortality [8-10]. Obesity may also be associated with developing CKD [11-13]. For dialysis patients, however, several studies have reported that the BMI is inversely related with mortality $[14,15]$ and BP [16]. These studies have suggested that dialysis patients, especially those with the malnutrition-inflammation syndrome, often lose weight $[14,15]$ or that obese patients sequester excess fluid volume in extracellular space more effectively than do lean people and therefore do not develop hypertension [16]. Thus, the BMI is likely to become less involved with BP and mortality with progression of CKD. Unlike the general population, changes in the body weight (BW) in CKD patients may be caused not only by changes in muscle and fat but also by the fluid status, suggesting that the BMI in such patients might not be merely a marker for obesity. Among the various factors that cause hypertension in patients with CKD, it is often difficult to differentiate between the influence of fluid volume imbalance that promotes fluid volume-dependent hypertension and the influence of either obesity or the malnutrition and inflammation syndrome promoting atherosclerosis-dependent hypertension.

The isotopic dilution technique $\left(\mathrm{D}_{2} \mathrm{O}\right)$ and dual energy X-ray absorptiometry (DEXA) are reliable methods for the measurement of total body water (TBW) [17]. However, these techniques are invasive and inconvenient to perform. Multi-frequency bioelectrical impedance analysis (MF-BIA) has been observed to be a suitable noninvasive alternative to these techniques [18]. MF-BIA can effectively distinguish between intra- and extracellular components. The values of $\mathrm{TBW}_{\mathrm{BIA}}$, intracellular water $\left(\mathrm{ICW}_{\mathrm{BIA}}\right)$, and extracellular water $\left(\mathrm{ECW}_{\mathrm{BIA}}\right)$ measured by MF-BIA have a high correlation with the corresponding values measured by $\mathrm{D}_{2} \mathrm{O}$ and DEXA [18]. In fact, the fat-free mass and the ratio of ECW to TBW measured by MF-BIA have been used for the assessment of fluid volume status in CKD patients $[19,20]$. However, fluid volume status cannot be distinguished from these indicators because the balance of ECW and ICW appears to change depending on the edematous status as well as the body type of patients, such as obese or lean [21,22]. In particular, individuals with the lean body type show an increased $\mathrm{ECW}_{\mathrm{BIA}} / \mathrm{TBW}_{\mathrm{BIA}}$ ratio with a decreased $\mathrm{ICW}_{\mathrm{BIA}}$ regardless of their edematous state $[21,22]$. A recent study has proposed a new 3-compartment model comprising normally hydrated adipose tissue mass, normally hydrated lean tissue mass and excess fluid mass [21]; the difference between the expected normal ECW obtained by calculation and the measured ECW value is used to assess the fluid volume status [23]. However, these methods need complicated formulae and the appropriate reference values. Thus, a reliable indicator of fluid volume status corresponding to body type in CKD patients remains unavailable.

Anthropometric formulae used in combination with tracer dilution techniques (e.g., Watson) have been widely used to calculate the $\mathrm{TBW}_{\text {Watson }}$ in CKD patients [24]. The Watson formula, which is routinely used when calculating dialysis efficiency, was originally derived from pooled data of healthy volunteers; it provides information regarding adequate fluid volume balance. Consequently, $\mathrm{TBW}_{\mathrm{BIA}}$ is the actual value of fluid volume and $\mathrm{TBW}_{\text {Watson }}$ provides the adequacy of fluid volume. The $\mathrm{TBW}_{\mathrm{BIA}} / \mathrm{TBW}_{\text {Watson }}$ ratio, which can be calculated using anthropometric formulae, may possibly be a practical tool for assessing the fluid volume. 


\section{Kidney \\ Blood Pressure Research}

Fig. 1. Frame format of the body fluid composition, assessment tools, and equations.

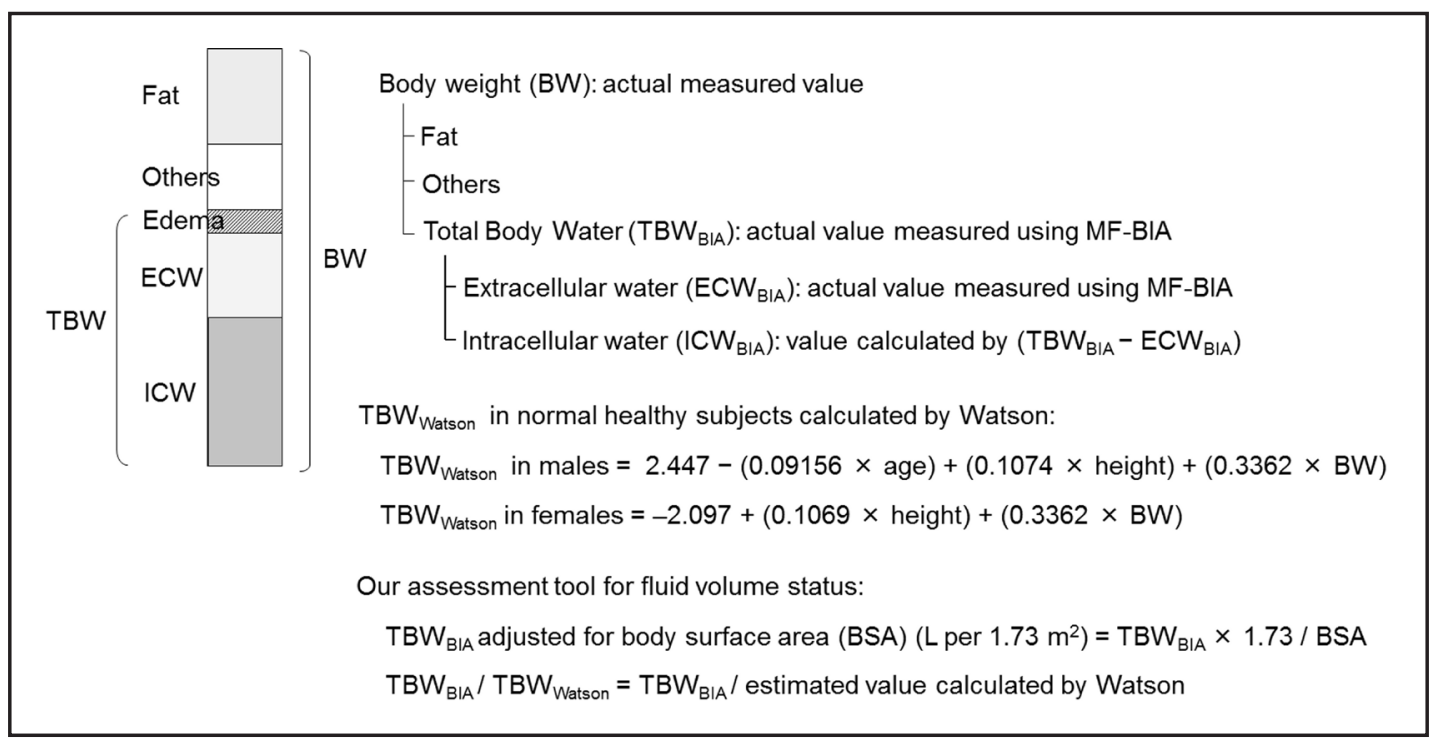

The present study aimed to assess the associations of body fluid composition and the BMI with 24-h ambulatory blood pressure (ABP) in CKD patient and to provide a reliable tool for assessing the fluid volume status.

\section{Materials and Methods}

\section{Study design}

We randomly selected 40 ambulatory patients with CKD from our kidney center to participate in this study. Informed consent was obtained from all the patients. This study was approved by the Ethics Committee of Toho University Omori Medical Center, Tokyo, Japan. CKD was diagnosed if any of the following parameters were met: estimated glomerular filtration rate (eGFR) $<60 \mathrm{~mL} \cdot \mathrm{min}^{-1}$ per $1.73 \mathrm{~m}^{2}$ for at least 3 months; presence of proteinuria (spot urine/protein ratio $\geq 300 \mathrm{mg} / \mathrm{g}$ creatinine); or the presence of structural kidney disease (e.g., adult polycystic kidney disease), according to the Kidney Disease Outcomes Quality Initiative and the position statement of Kidney Disease: Improving Global Outcomes [25]. The participants were surveyed for age, gender, height, body weight, BMI, underlying disease, BP, serum albumin (Alb), total cholesterol (TC) to high-density lipoprotein (HDL) ratio, low-density lipoprotein (LDL) to high-density lipoprotein (HDL) ratio, uric acid (UA), eGFR, proteinuria, and prescription of diuretics and antihypertensive agents. Hyperuricemia was diagnosed when the uric acid level was $>7.0 \mathrm{mg} / \mathrm{dL}$ and $>6.0$ $\mathrm{mg} / \mathrm{dL}$ in male and female patients, respectively. The eGFR was calculated according to the revised formula of $\left[194 \times \mathrm{Cr}^{-1.094} \times \mathrm{Age}^{-0.287}\right](\times 0.739$ for women $)$ for Japanese patients according to the Modification of Diet in Renal Disease method [26].

To assess the components of body fluid composition, we used the assessment methods and equations described in Figure 1. MF-BIA was performed in the standard manner with the patient lying supine on a flat nonconductive bed for at least $15 \mathrm{~min}$. For the determination of $\mathrm{TBW}_{\mathrm{BIA}}$, we used a segmental MFBIA instrument (Inbody S20 ${ }^{\circledR}$;Biospace Co. Ltd., Seoul, Korea; www.biospaceamerica.com), which has 8 tactile electrodes. The microprocessor-controlled switches and impedance analyzer were activated and the segmental resistances of the arms, trunk, and legs were measured at 4 frequencies $(5,50,250$, and $500 \mathrm{kHz})$. Thus, a set of 20 segmental resistances was measured for each individual. These data were then used to calculate $\mathrm{TBW}_{\mathrm{BIA}}$ from the sum of the measurements for each body segment by using MF-BIA software. The measured $\mathrm{TBW}_{\mathrm{BIA}}$ was expressed as actual values, percentages of BW, and corrected values for body surface area (BSA) $\left(\mathrm{cTBW}_{\mathrm{BIA}}\right)$. TBW ${ }_{\text {Watson }}$ was calculated according to the Watson formula [24]; then, the $\mathrm{TBW}_{\mathrm{BIA}} /$ $\mathrm{TBW}_{\text {Watson }}$ ratio was calculated. The $\mathrm{CTBW}_{\mathrm{BIA}}$ and $\mathrm{TBW}_{\mathrm{BIA}} / \mathrm{TBW}_{\text {Watson }}$ ratio were used to assess the fluid volume status. 


\section{Kidney \\ Blood Pressure Research}

Kidney Blood Press Res 2012;36:231-241

\begin{tabular}{l|l}
\hline DOI: $10.1159 / 000343412$ & C 2012 S. Karger AG, Basel
\end{tabular}

Published online: November 19, 2012

www.karger.com/kbr

Ohashi/Otani/Tai et al.: Circadian BP and Body Composition in CKD

ABP was measured every $20 \mathrm{~min}$ (6:00 AM to 10:00 PM) during the day and every $30 \mathrm{~min}$ at night (10:00 PM to 6:00 AM) using automated ABP monitors on the arm. In this study, patients with $<8 \mathrm{~h}$ of $\mathrm{ABP}$ recordings were considered to have inadequate measurements and were excluded from the analysis. Average 24-h ABP values of $\geq 135 / 85 \mathrm{mmHg}$ were considered as elevated ABP [27] regardless of antihypertensive agent use. Nocturnal non-dipping was defined as a decrease of $<10 \%$ in systolic BP during sleep as compared with that during the awaking period [28].

\section{Statistical Analysis}

Data were statistically analyzed using JMP version 9.0 software (SAS Institute Inc, Cary, NC). Homogeneity of variances was analyzed using Bartlett's test. When the variances of the 2 groups were assumed to be equal, statistical significance for the 2 groups was assessed using Student's $t$-test for continuous variables, as appropriate, and Pearson's $\chi^{2}$ test or Fisher's exact test for categorical variables. The measured values were expressed as mean \pm standard deviation (SD) and percentages. The significance of the correlations between the $\mathrm{CTBW}_{\mathrm{BIA}}$ and $\mathrm{TBW}_{\mathrm{BIA}} / \mathrm{TBW}_{\text {Watson }}$ ratio values and the variables of $24-\mathrm{h} \mathrm{ABP}$ were analyzed using Pearson product-moment correlation coefficient. The variables that showed a $p$-value of $<0.20$ in the correlation coefficients were analyzed using stepwise linear regression analysis to exclude confounding factors. The analyzed values were expressed as standardized partial regression coefficient \pm standard error (SE) in the stepwise multivariate linear regression model. A $p$-value of $<0.05$ was considered statistically significant.

\section{Results}

Associations of demographic characteristics with circadian blood pressure

Table 1 presents the relevant baseline characteristics of the 40 study participants in relation to the presence or absence of elevated $\mathrm{ABP}$ and nocturnal non-dipping. Twentythree (57.5\%) patients showed elevated ABP; these patients were more likely to be younger and have diabetes mellitus (DM), lower eGFR, increased proteinuria, and lower Alb levels than the patients without elevated ABP. The 2 groups did not differ significantly with respect to the lipid profile, uric acid level, and prescription of diuretics and antihypertensive agents. In this population, $26(65.0 \%)$ patients showed nocturnal non-dipping; these patients were more likely to have DM and lower Alb levels than patients with nocturnal dipping.

\section{Associations of demographic characteristics with body fluid composition and BMI}

Tables 2 and 3 present the associations of demographic variables with the CTBW ${ }_{\text {BIA' }}$ the $\mathrm{TBW}_{\mathrm{BIA}} / \mathrm{TBW}_{\text {Watson }}$ ratio, and the BMI. The $\mathrm{CTBW}_{\text {BIA }}$ showed an independent positive association with male gender, BMI, and furosemide use and negative association with age. In contrast, the $\mathrm{TBW}_{\mathrm{BIA}} / \mathrm{TBW}_{\text {Watson }}$ ratio was independently positively associated with DM and furosemide use. The BMI was negatively correlated with age and was positively correlated with furosemide use, any 1 or more diuretics use, and any 3 or more antihypertensives use. However, there were no independent demographic factors for the BMI after adjusting for age, DM, TC/HDL ratio, furosemide use, and any 3 or more antihypertensives use.

\section{Associations of body fluid composition and BMI with circadian blood pressure}

Figure 2 presents the body fluid composition obtained by MF-BIA and the Watson formula and BMI in relation to the presence or absence of elevated ABP and nocturnal nondipping. The $\mathrm{CTBW}_{\mathrm{BIA}}$ and $\mathrm{TBW}_{\mathrm{BIA}} / \mathrm{TBW}_{\text {Watson }}$ ratio values were more likely to be significantly higher in patients with elevated ABP (cTBW ${ }_{\text {BIA }}: 33.1 \pm 5.5 \mathrm{~L}$ vs. $35.2 \pm 5.1 \mathrm{~L}, p<0.05$, and $\mathrm{TBW}_{\text {BIA }} / \mathrm{TBW}_{\text {Watson }}$ ratio: $0.952 \pm 0.064$ vs. $1.010 \pm 0.050, p<0.01$ ). Further, the $\mathrm{TBW}_{\mathrm{BIA}} /$ $\mathrm{TBW}_{\text {Watson }}$ ratio was more likely to be significantly higher in patients with nocturnal nondipping than in those without nocturnal non-dipping $(0.952 \pm 0.054 \mathrm{~L}$ vs. $1.000 \pm 0.060 \mathrm{~L}$, $p<0.05$ ), but there was no significant difference in the cTBW $_{\text {BIA }}$ between patients with and without nocturnal non-dipping. BMI showed no significant differences between the presence and absence of elevated ABP and nocturnal non-dipping. 


\section{Kidney Blood Pressure Research}

Table 1: Clinical characteristics according to the presence of elevated average 24-h blood pressure and nocturnal non-dipping

\begin{tabular}{|c|c|c|c|c|c|c|c|}
\hline \multirow[b]{2}{*}{ Characteristics } & \multirow[b]{2}{*}{ Overall } & \multicolumn{2}{|c|}{ 24-h ambulatory BP } & \multirow[b]{2}{*}{$p$} & \multicolumn{2}{|c|}{ Nocturnal dipping } & \multirow[b]{2}{*}{$p$} \\
\hline & & $\begin{array}{c}<135 / 85 \\
\mathrm{mmHg}\end{array}$ & $\begin{array}{c}\geq 135 / 85 \\
\mathrm{mmHg}\end{array}$ & & $\geq 10 \%$ & $<10 \%$ & \\
\hline Number, $\mathrm{n}$ & 40 & $17(42.5)$ & $23(57.5)$ & & $14(35.0)$ & $26(65.0)$ & \\
\hline Age, years & $68.7 \pm 11.6$ & $73.1 \pm 11.3$ & $65.5 \pm 11.0$ & 0.040 & $70.3 \pm 12.2$ & $67.9 \pm 11.4$ & 0.539 \\
\hline Gender female, n (\%) & $7(17.5)$ & $3(17.6)$ & $4(17.4)$ & 1.000 & $3(21.4)$ & $4(15.4)$ & 0.679 \\
\hline BW, kg & $64.1 \pm 11.2$ & $61.6 \pm 11.8$ & $66.0 \pm 10.6$ & 0.223 & $62.0 \pm 10.4$ & $65.3 \pm 11.7$ & 0.386 \\
\hline BMI, $\mathrm{kg} / \mathrm{m}^{2}$ & $24.4 \pm 3.5$ & $23.8 \pm 3.7$ & $24.9 \pm 3.3$ & 0.359 & $23.7 \pm 2.9$ & $24.8 \pm 3.7$ & 0.354 \\
\hline Diabetes mellitus, n (\%) & $17(42.5)$ & $3(17.6)$ & $14(60.9)$ & 0.010 & $3(21.4)$ & $14(53.9)$ & 0.048 \\
\hline eGFR, $\mathrm{mL} / \mathrm{min}$ per $1.73 \mathrm{~m}^{2}$ & $26.0 \pm 16.6$ & $32.1 \pm 18.7$ & $21.6 \pm 13.1$ & 0.042 & $30.9 \pm 20.0$ & $23.4 \pm 13.7$ & 0.170 \\
\hline Proteinuria, g/g creatinine & $1.9 \pm 2.7$ & $0.3 \pm 0.7$ & $3.1 \pm 3.0$ & $<0.001$ & $1.2 \pm 2.7$ & $2.4 \pm 2.6$ & 0.178 \\
\hline Alb, g/dL & $3.8 \pm 0.5$ & $4.0 \pm 0.3$ & $3.6 \pm 0.6$ & 0.003 & $4.0 \pm 0.3$ & $3.6 \pm 0.6$ & 0.039 \\
\hline TC/HDL & $4.1 \pm 1.8$ & $3.8 \pm 2.1$ & $4.3 \pm 1.7$ & 0.439 & $4.3 \pm 2.5$ & $4.0 \pm 1.4$ & 0.732 \\
\hline LDL/HDL & $2.4 \pm 1.3$ & $2.1 \pm 1.7$ & $2.6 \pm 1.1$ & 0.413 & $2.4 \pm 1.8$ & $2.4 \pm 1.0$ & 0.872 \\
\hline Hyperuricemia, n (\%) & $27(67.5)$ & $9(52.9)$ & $18(78.3)$ & 0.082 & $9(64.3)$ & $18(69.2)$ & 0.723 \\
\hline \multicolumn{8}{|l|}{ Diuretics } \\
\hline Thiazide, n (\%) & $3(7.5)$ & $0[0.0]$ & $3(13.0)$ & 0.248 & $1(7.1)$ & $2(7.7)$ & 1.000 \\
\hline Furosemide, n (\%) & $13(32.5)$ & $4(23.5)$ & $9(39.1)$ & 0.333 & $4(28.6)$ & $9(34.6)$ & 1.000 \\
\hline Aldosterone antagonist, $\mathrm{n}(\%)$ & $3(7.5)$ & $1(5.9)$ & $2(8.7)$ & 1.000 & $1(7.1)$ & $2(7.7)$ & 1.000 \\
\hline Any 1 of the above diuretics, $n(\%)$ & $15(37.5)$ & $5(29.4)$ & $10(43.5)$ & & $6(42.9)$ & $9(34.6)$ & \\
\hline Any 2 of the above diuretics, $n(\%)$ & $2(5.0)$ & $0(0.0)$ & $2(8.7)$ & 0.325 & $0(0.0)$ & $2(7.7)$ & 0.873 \\
\hline \multicolumn{8}{|l|}{ Antihypertensives } \\
\hline ACE inhibitors, $n(\%)$ & $8(20.0)$ & $4(23.5)$ & $4(17.4)$ & 0.703 & $3(21.4)$ & $5(19.2)$ & 1.000 \\
\hline AT1-R blocker, n (\%) & $34(85.0)$ & $13(76.5)$ & $21(91.3)$ & 0.373 & $11(78.6)$ & $23(88.5)$ & 0.646 \\
\hline Ca channel blocker, n (\%) & $27(67.5)$ & 10 (58.8) & $17(73.9)$ & 0.496 & $8(57.1)$ & $19(73.1)$ & 0.480 \\
\hline$\beta$-blocker, n (\%) & $6(15.0)$ & $3(17.6)$ & $3(13.0)$ & 1.000 & $2(14.3)$ & $4(15.4)$ & 1.000 \\
\hline$\alpha$-blocker, n (\%) & $5(15.0)$ & $1(5.9)$ & $4(17.4)$ & 0.373 & $1(7.1)$ & $4(15.4)$ & 0.640 \\
\hline Number of antihypertensives, $\mathrm{n}$ & $2.5 \pm 1.3$ & $1.8 \pm 0.8$ & $2.1 \pm 1.0$ & 0.310 & $1.8 \pm 0.9$ & $2.1 \pm 1.0$ & 0.293 \\
\hline
\end{tabular}

Table 4 presents the associations of demographic characteristics and body fluid status with the average systolic 24-h ABP and the average diastolic 24-h ABP. Model 1 in Table 4 shows the $\beta$-coefficients of variables for these dependent variables concerning the cTBW $_{\text {BIA }^{\prime}}$ and Model 2 in Table 4 shows these values for variables concerning the TBW $_{\text {BIA }} /$ $\mathrm{TBW}_{\text {Watson }}$ ratio. After adjusting for multiple variables by stepwise linear regression analysis, proteinuria of $\geq 1.0 \mathrm{~g} / \mathrm{g}$ creatinine remained a significant independent factor for the average systolic and diastolic 24-h ABP in Model 1 and 2, and age remained a significant independent factor for the average diastolic 24-h ABP in Model 1. The $\mathrm{TBW}_{\mathrm{BIA}} / \mathrm{TBW}_{\text {Watson }}$ ratio remained significant independent factors for the average systolic 24-h ABP in Model 2. However, there were no significant independent factors for nocturnal non-dipping.

Associations of the $\mathrm{cTBW}_{\mathrm{BIA}}$ and the $\mathrm{TBW}_{\text {BIA }} / \mathrm{TBW}_{\text {Watson }}$ ratio with BMI

Correlations of the BMI with the $\mathrm{CTBW}_{\mathrm{BIA}}$ and the $\mathrm{TBW}_{\mathrm{BIA}} / \mathrm{TBW}_{\text {Watson }}$ ratio are presented in Figure 3. The BMI was intermediately correlated with the $\operatorname{cTBW}_{\mathrm{BIA}}(r=0.520, p<0.001)$, which was an independent associate factor, and weakly correlated with the $\mathrm{TBW}_{\mathrm{BIA}} / \mathrm{TBW}_{\text {Watson }}$ ratio $(r=0.323, p<0.05)$.

\section{Discussion}

This present study revealed the association of body fluid composition with 24-h ABP and the association between TBW and BMI in patients with CKD. The study results suggested the following: (1) Patients with elevated ABP are more likely to have higher $\mathrm{CTBW}_{\mathrm{BIA}}$ and $\mathrm{TBW}_{\mathrm{BIA}} / \mathrm{TBW}_{\text {Watson }}$ ratio values, and patients with nocturnal non-dipping are more likely to 


\section{Kidney \\ Blood Pressure Research}

Table 2: Correlations of demographic variables with $\mathrm{cTBW}_{\mathrm{BIA}}, \mathrm{TBW}_{\mathrm{BIA}} / \mathrm{TBW}_{\text {Watson' }}$, and BMI

\begin{tabular}{|c|c|c|c|c|c|c|}
\hline \multirow[t]{2}{*}{ Variables } & \multicolumn{2}{|c|}{$\begin{array}{c}\text { cTBW } W_{\text {BIA }} \\
\left(\text { L per } 1.73 \mathrm{~m}^{2}\right)\end{array}$} & \multicolumn{2}{|c|}{$\mathrm{TBW}_{\mathrm{BIA}} / \mathrm{TBW}_{\text {Watson }}$} & \multicolumn{2}{|c|}{ BMI $\left(\mathrm{kg} / \mathrm{m}^{2}\right)$} \\
\hline & $\beta$ & $p$ & $\beta$ & $p$ & $\beta$ & $p$ \\
\hline Age, years & -0.510 & $<0.001$ & -0.320 & 0.044 & -0.378 & 0.016 \\
\hline Male gender & 0.554 & $<0.001$ & 0.293 & 0.067 & -0.029 & 0.860 \\
\hline Diabetes mellitus & 0.361 & 0.022 & 0.386 & 0.014 & 0.232 & 0.150 \\
\hline $\mathrm{BMI}, \mathrm{kg} / \mathrm{m}^{2}$ & 0.523 & $<0.001$ & 0.330 & 0.038 & - & - \\
\hline eGFR, mL/min per $1.73 \mathrm{~m}^{2}$ & -0.046 & 0.777 & -0.138 & 0.396 & 0.085 & 0.603 \\
\hline Proteinuria $\geq 1.0 \mathrm{~g} / \mathrm{g}$ creatinine & 0.265 & 0.099 & 0.267 & 0.096 & 0.198 & 0.221 \\
\hline $\mathrm{Alb}, \mathrm{g} / \mathrm{dL}$ & -0.254 & 0.114 & -0.370 & 0.019 & 0.078 & 0.630 \\
\hline TC/HDL & 0.013 & 0.949 & 0.111 & 0.580 & 0.258 & 0.193 \\
\hline LDL/HDL & $<0.001$ & 0.997 & 0.121 & 0.549 & 0.238 & 0.231 \\
\hline Hyperuricemia & 0.097 & 0.557 & -0.064 & 0.698 & 0.030 & 0.854 \\
\hline Thiazide & 0.101 & 0.534 & 0.004 & 0.982 & 0.141 & 0.387 \\
\hline Furosemide & 0.356 & 0.024 & 0.379 & 0.016 & 0.358 & 0.023 \\
\hline Aldosterone antagonist & 0.053 & 0.743 & $<0.001$ & 0.999 & -0.118 & 0.913 \\
\hline Any 1 or more of the above diuretics & 0.211 & 0.192 & 0.276 & 0.084 & 0.375 & 0.017 \\
\hline ACE inhibitors & 0.188 & 0.245 & 0.112 & 0.492 & 0.177 & 0.274 \\
\hline AT1-R blocker & 0.139 & 0.393 & 0.239 & 0.137 & -0.125 & 0.441 \\
\hline Ca channel blocker & 0.025 & 0.881 & -0.038 & 0.816 & 0.062 & 0.702 \\
\hline$\beta$-blocker & 0.068 & 0.675 & 0.182 & 0.260 & 0.066 & 0.687 \\
\hline$\alpha$-blocker & 0.032 & 0.845 & 0.094 & 0.563 & 0.302 & 0.059 \\
\hline Any 3 or more antihypertensives & 0.258 & 0.107 & 0.302 & 0.059 & 0.325 & 0.041 \\
\hline \multicolumn{7}{|c|}{$\begin{array}{l}\text { Abbreviations: CTBW } \text { BIA, total body water determined using bioelectrical impedance analysis adjusted for body }_{\text {surface area; TBW }} \text { BIA, total body water determined using bioelectrical impedance analysis; TBW Watson, total body } \\
\text { water determined using Watson formula; BMI, body mass index; eGFR, estimated glomerular filtration rate; Alb, } \\
\text { serum albumin; TC, total cholesterol; HDL, high-density lipoprotein; LDL, low-density lipoprotein; ACE, angiotensin } \\
\text { converting enzyme; AT1-R, angiotensin II type } 1 \text { receptor }\end{array}$} \\
\hline
\end{tabular}

Table 3: Stepwise multivariate linear regression models for cTBW $_{\text {BIA }}$ and $\mathrm{TBW}_{\mathrm{BIA}} / \mathrm{TBW}_{\text {Watson }} *$ (*Only statistically significant differences are presented. Explanatory variables were selected on the basis of a $p$ value of $<0.20$ in the prior univariate analysis. Variables included in the stepwise multivariate linear regression models for $\mathrm{CTBW}_{\text {BIA }}$ and $\mathrm{TBW}_{\mathrm{BIA}} / \mathrm{TBW}_{\text {Watson }}$ were age, male gender, diabetes mellitus, body mass index, proteinuria $\geq$ $1.0 \mathrm{~g} / \mathrm{g}$ creatinine, furosemide, and angiotensin II type 1 receptor

\begin{tabular}{lccc}
\hline & $\beta$ & SE & $p$ \\
\hline$c T B W_{B I A}$ L per $1.73 m^{2}$ & & & \\
Age, years & -0.414 & 0.029 & $<0.001$ \\
Male gender & 0.574 & 0.404 & $<0.001$ \\
BMI, kg/m ${ }^{2}$ & 0.307 & 0.160 & 0.003 \\
Furosemide & 0.211 & 0.539 & 0.024 \\
TBW $W_{\text {BIA }} /$ TBW Watson & & & \\
Diabetes mellitus & 0.334 & 0.009 & 0.026 \\
Furosemide & 0.326 & 0.009 & 0.030 \\
\hline
\end{tabular}

Abbreviations: : cTBW $\mathrm{BI}$, total body water by using bioelectrical impedance analysis adjusted for body surface area; BMI, body mass index; TBW $\mathrm{BIA}$, total body water determined using bioelectrical impedance analysis; TBW Watson, total body water determined using the Watson formula

(AT1-R) blocker. Albumin, number of diuretics, and number of antihypertensives were not included in these analyses because these variables may possibly have had multicollinearity for proteinuria, furosemide, and AT1-R blocker, respectively)

have higher $\mathrm{TBW}_{\mathrm{BIA}} / \mathrm{TBW}_{\text {Watson }}$ ratios, whereas $\mathrm{BMI}$ is not associated with elevated $\mathrm{ABP}$ and nocturnal non-dipping; (2) proteinuria is an independent factor for average 24-h ABP, and $\mathrm{TBW}_{\mathrm{BIA}} / \mathrm{TBW}_{\text {Watson }}$ ratio is an independent factor for average systolic 24-h ABP; and (3) BMI has a positive correlation with the $\mathrm{CTBW}_{\mathrm{BIA}}$ and the $\mathrm{TBW}_{\mathrm{BIA}} / \mathrm{TBW}_{\text {Watson }}$ ratio. 


\section{Kidney Blood Pressure Research}

Fig. 2. Box plots of $\mathrm{CTBW}_{\mathrm{BIA}}$ (A and B), $\mathrm{TBW}_{\mathrm{BIA}} / \mathrm{TBW}_{\text {Watson }}$ ( $C$ and $\mathrm{D}$ ) and BMI ( $\mathrm{E}$ and $\mathrm{F}$ ) according to the presence of elevated ABP and nocturnal non-dipping. $\mathrm{ABP}$, ambulatory blood pressure; CTBW $_{\text {BIA' }}$ total body water by using bioelectrical impedance analysis adjusted for body surface area; $\mathrm{TBW}_{\mathrm{BIA}}$, total body water determined using bioelectrical impedance analysis; $\mathrm{TBW}_{\text {Watson' }}$ total body water determined using the Watson formula.
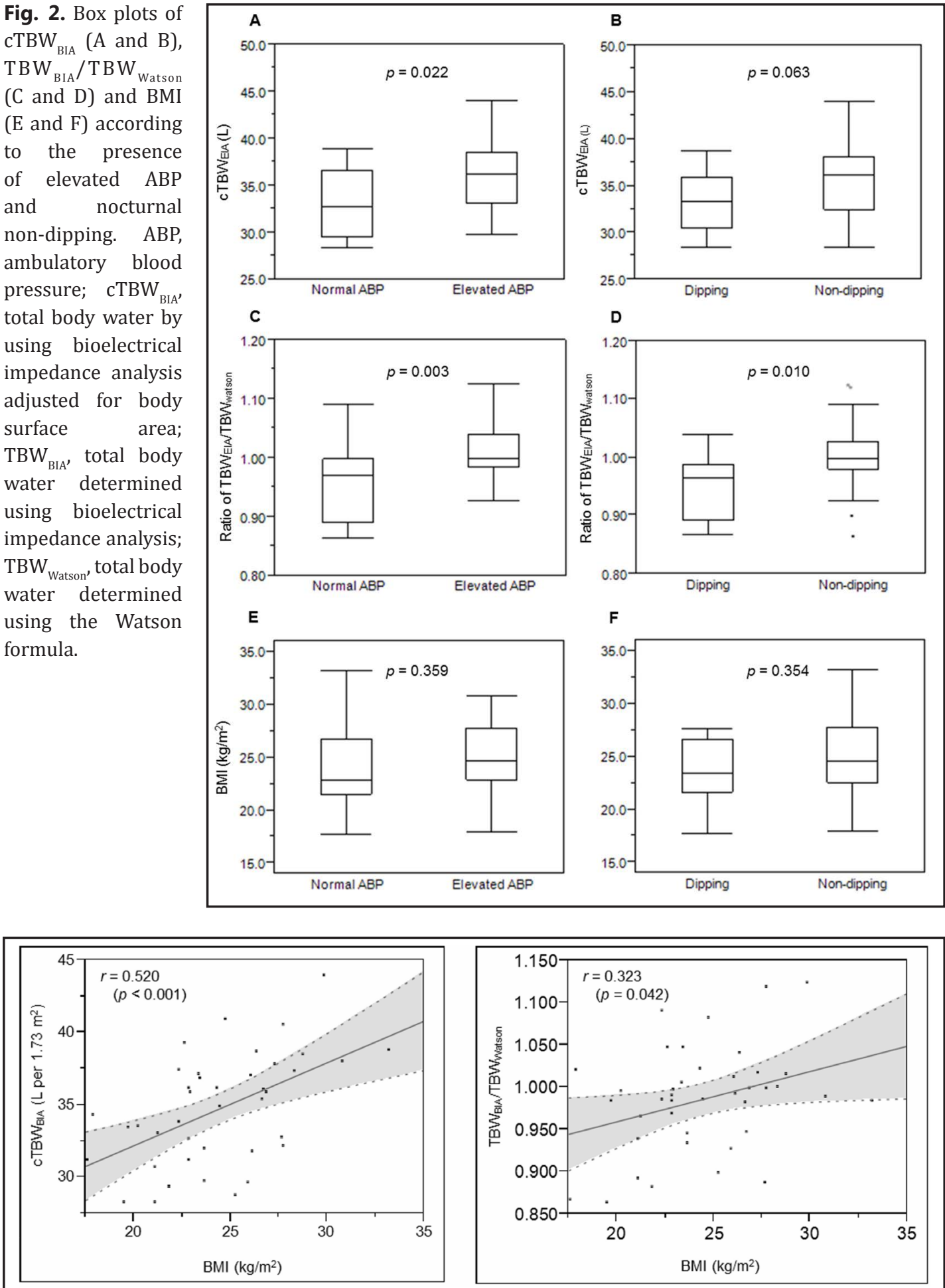

Fig. 3. Correlations of BMI with cTBW ${ }_{B I A}$ and $\mathrm{TBW}_{\mathrm{BIA}} / \mathrm{TBW}_{\text {Watson }}$. Abbreviations: $\mathrm{CTBW}_{\mathrm{BI}}$, total body water by using bioelectrical impedance analysis adjusted for body surface area; $\mathrm{TBW}_{\mathrm{BI},}$, total body water determined using bioelectrical impedance analysis; $\mathrm{TBW}_{\text {Watson }}$, total body water determined using the Watson formula.

Obesity is an independent risk factor for hypertension [8-10] and CKD [11-13]. Nevertheless, the relationship between BMI and BP is attenuated in advanced CKD, and BMI 


\section{Kidney \\ Blood Pressure Research}

Table 4: Stepwise multivariate linear regression models for average 24-h blood pressure* ${ }^{*}$ Only statistically significant differences are presented. Explanatory variables were selected on the basis of a $p$ value of $<0.20$ in the prior univariate analysis. Model 1 shows the $\beta$ coefficients for average 24-h blood pressure by variables involving $\mathrm{CTBW}_{\mathrm{BIA}}$, and model 2 shows those by variables involving $\mathrm{TBW}_{\mathrm{BIA}} / \mathrm{TBW}_{\text {Watson }}$. Variables included in the stepwise multivariate linear regression models for average 24-h systolic blood pressure (BP) were age, diabetes mellitus, estimated glomerular filtration rate (eGFR), proteinuria $\geq 1.0 \mathrm{~g} / \mathrm{g}$ creatinine, hyperuricemia, and cTBW $_{\text {BIA }}$ or $\mathrm{TBW}_{\mathrm{BIA}} / \mathrm{TBW}_{\text {Watson }}$ and for average 24-h diastolic BP were age, diabetes mellitus, eGFR, proteinuria $\geq 1.0 \mathrm{~g} / \mathrm{g}$ creatinine, and $\mathrm{cTBW} \mathrm{BIA}_{\mathrm{A}}$ or $\mathrm{TBW}_{\mathrm{BIA}} / \mathrm{TBW}_{\text {Watson }}$ )

is inversely associated with BP and mortality in dialysis patients [16]. The interrelationship of malnutrition inflammation and arteriosclerosis (MIA) in leaner dialysis patients is known as one of the best answers for the paradox between BMI, hypertension, and mortality $[14,15]$. In addition, unlike the general population, we assumed that hypertension in CKD patients is related more closely to fluid volume status than to BMI. Our data suggest that proteinuria and fluid volume imbalance are more important dependent factors for 24-h ABP than BMI in patients with CKD and that the association of proteinuria with 24-h ABP is independent with respect to fluid volume status. Hyperfiltration with increased BP may lead to increased proteinuria, or proteinuria may mediate a persistent increase in renin-angiotensin activity [29].

In our study, BMI was correlated with the $\mathrm{CTBW}_{\mathrm{BIA}}$ and the $\mathrm{TBW}_{\mathrm{BIA}} / \mathrm{TBW}_{\text {Watson }}$ ratio, and furosemide use was positively correlated with BMI. This finding supported our assertion that BMI is partially affected by the fluid volume status in CKD patients. Moreover, BMI was not associated with elevated ABP or nocturnal non-dipping. This result suggests that factors other than obesity, such as proteinuria and fluid volume imbalance, are associated with 24-h ABP. Furthermore, the CTBW ${ }_{\text {BIA }}$, i.e., the ratio of TBW to BSA, was observed to decrease with age (Tables 2 and 3). It is thus difficult to assess body composition and elucidate the relationship between BP, fluid volume status, and nutritional status in patients with CKD.

Although many studies have investigated the fluid volume status by using MF-BIA in CKD patients, only a few studies have reported the association between the fluid volume status and the circadian rhythm of BP. One of the reasons for the dearth of studies is possibly the absence of a practical and reliable indicator of the fluid volume imbalance. We assessed the fluid volume status in $\mathrm{CKD}$ patients using the $\mathrm{TBW}_{\mathrm{BIA}} / \mathrm{TBW}_{\text {Watson }}$ ratio calculated using the Watson formula adjusted for height, weight, age, and gender [24]. This ratio may diminish the impact of these factors on the measurement of fluid volume status, and the difference between $\mathrm{TBW}_{\mathrm{BIA}}$ and $\mathrm{TBW}_{\text {Watson }}$ reflects changes in the TBW in terms of the imbalance in the fluid volume status. cTBW ${ }_{\text {BIA }}$ adjusted for BSA may be a practical indicator because reference values are not required for its use. However, this parameter cannot be adjusted for the factors of age and gender. The $\mathrm{TBW}_{\mathrm{BIA}} / \mathrm{TBW}_{\text {Watson }}$ ratio showed a significant association with 24-h

\begin{tabular}{|c|c|c|c|}
\hline & $\beta$ & SE & $p$ \\
\hline \multicolumn{4}{|l|}{ Model1 } \\
\hline \multicolumn{4}{|l|}{ Average 24- $h \mathrm{SBP}, \mathrm{mmHg}$} \\
\hline Proteinuria $\geq 1.0 \mathrm{~g} / \mathrm{g}$ creatinine & 0.626 & 2.220 & $<0.001$ \\
\hline \multicolumn{4}{|l|}{ Average 24-h DBP, $\mathrm{mmHg}$} \\
\hline Age, years & -0.449 & 0.122 & 0.003 \\
\hline Proteinuria $\geq 1.0 \mathrm{~g} / \mathrm{g}$ creatinine & 0.286 & 1.398 & 0.047 \\
\hline \multicolumn{4}{|l|}{ Model 2} \\
\hline \multicolumn{4}{|l|}{ Average 24-h SBP, $\mathrm{mmHg}$} \\
\hline Proteinuria $\geq 1.0 \mathrm{~g} / \mathrm{g}$ creatinine & 0.556 & 2.207 & $<0.001$ \\
\hline $\mathrm{TBW}_{\mathrm{BIA}} / \mathrm{TBW}_{\text {Watson }}$ & 0.263 & 35.776 & 0.043 \\
\hline \multicolumn{4}{|l|}{ Average 24-h DBP, $\mathrm{mmHg}$} \\
\hline Age, years & -0.449 & 0.122 & 0.003 \\
\hline Proteinuria $\geq 1.0 \mathrm{~g} / \mathrm{g}$ creatinine & 0.286 & 1.398 & 0.047 \\
\hline \multicolumn{4}{|c|}{$\begin{array}{l}\text { Abbreviations: SBP, systolic blood pressure; DBP, diastolic blood } \\
\text { pressure; TBW } \text { BIA, total body water determined using bioelectrical } \\
\text { impedance analysis; TBWWatson, total body water determined using the } \\
\text { Watson formula }\end{array}$} \\
\hline
\end{tabular}




\section{Kidney \\ Blood Pressure Research}

systolic ABP, being more likely to be higher in patients with elevated ABP and nocturnal nondipping. This finding was partly supported by the results of previous studies, which reported that CKD induced the salt-sensitive type of hypertension that causes elevated nocturnal BP due to a defect in the sodium excretory capability [30]. The $\mathrm{TBW}_{\mathrm{BIA}} / \mathrm{TBW}_{\text {Watson }}$ ratio can serve as an indicator of fluid volume-dependent hypertension. In this regard, however, the $\mathrm{TBW}_{\mathrm{BIA}} /$ $\mathrm{TBW}_{\text {Watson }}$ ratio should be interpreted with caution because of the SD obtained using the Watson formula (3.76 in men and 3.60 in women) [20]. Further, the $\mathrm{TBW}_{\mathrm{BIA}} / \mathrm{TBW}_{\text {Watson }}$ ratio was less than 1.0 in all the patients, suggesting that $\mathrm{TBW}_{\text {Watson }}$ may have been overestimated in the general Japanese population. A previous study reported differences in $\mathrm{TBW}_{\text {Watson }}$ across individuals depending on race [31]. If the $\mathrm{TBW}_{\mathrm{BIA}} / \mathrm{TBW}_{\text {Watson }}$ ratio is applied more practically, a precise value of TBW in the Japanese population can be estimated, so that a reference range for the $\mathrm{TBW}_{\mathrm{BIA}} / \mathrm{TBW}_{\text {Watson }}$ ratio can be established in the future by using catamnestic data.

Previous studies have reported the indications and limitations of body composition analysis using MF-BIA [32-35]. Cooper et al. compared the results of TBW assessment in CKD patients by using different methods such as $\mathrm{D}_{2} \mathrm{O}$, Watson formula, MF-BIA, and calculating the TBW as 58\% of the BW [32]. According to their reports, the Watson formula significantly underestimated the TBW. However, the mean TBW measured using MF-BIA did not differ significantly from the mean $\mathrm{D}_{2} \mathrm{O}$ value, and the reliability of the results did not vary enormously. Woodrow et al. reported more errors with BIA than with $\mathrm{D}_{2} \mathrm{O}$ and DEXA for TBW measurement in CKD patients [32,33]. However, these reports did not completely deny the value of TBW assessment by MF-BIA. MF-BIA is more accurate than anthropometric measurements and can be performed simply, conveniently, and non-invasively, in contrast to $\mathrm{D}_{2} \mathrm{O}$ and DEXA measurements. In this study, we did not assess $\mathrm{D}_{2} \mathrm{O}$ and DEXA because this study did not focus on the mechanical accuracy and advantages of MF-BIA. Even if the values for body composition established by $\mathrm{D}_{2} \mathrm{O}$ and DEXA are used, no complete consensus exists regarding a suitable indicator of fluid volume imbalance.

Our study has several limitations: this is a retrospective, cross-sectional study based on pre-existing medical records obtained from a single center, and the sample size is small. A prospective, multicenter epidemiological study on a larger scale is required to identify and establish the reference threshold for the $\mathrm{TBW}_{\mathrm{BIA}} / \mathrm{TBW}_{\text {Watson }}$ ratio. In addition, we observed that the estimated TBW may have an error margin in comparison to the actual value of TBW in the Japanese population. However, despite these limitations, we consider that the $\mathrm{TBW}_{\mathrm{BIA}} /$ $\mathrm{TBW}_{\text {Watson }}$ ratio has a practical use as an indicator of fluid volume-dependent hypertension.

\section{Conclusion}

Hypertension is dependent primarily on proteinuria and fluid volume imbalance in patients with CKD. The $\mathrm{TBW}_{\mathrm{BIA}} / \mathrm{TBW}_{\text {Watson }}$ ratio can serve as an indicator of fluid volumedependent hypertension. Unlike the general population, $\mathrm{BMI}$ is influenced by not only fat but also by TBW, in which case BMI can become less involved with 24-h ABP.

\section{Conflict of Interests}

The authors do not have any financial or other interests. The authors alone are responsible for the content and writing of this paper.

\section{Acknowledgements}

We wish to thank Dr. Sonoo Mizuiri for giving us the chance to initiate this study. 


\section{Kidney \\ Blood Pressure Research}

Kidney Blood Press Res 2012;36:231-241

\begin{tabular}{l|l}
\hline DOI: $10.1159 / 000343412$ & (C) 2012 S. Karger AG, Basel
\end{tabular}

Published online: November 19, 2012

www.karger.com/kbr

Ohashi/Otani/Tai et al.: Circadian BP and Body Composition in CKD

\section{References}

1 Whaley-Connell AT, Sowers JR, Stevens LA, McFarlane SI, Shlipak MG, Norris KC, Chen SC, Qiu Y, Wang C, Li S, Vassalotti JA, Collins AJ: In: Kidney Early Evaluation Program Investigators: CKD in the United States: Kidney Early Evaluation Program (KEEP) and National Health and Nutrition Examination Survey (NHANES) 1999-2004. Am J Kidney Dis 2008;51:S13-S20.

2 Neumann J, Ligtenberg G, Klein II, Koomans HA, Blankestijn PJ: Sympathetic hyperactivity in chronic kidney disease: pathogenesis, clinical relevance, and treatment. Kidney Int 2004;65:1568-1576.

-3 Raine AE, Bedford L, Simpson AW, Ashley CC, Brown R, Woodhead JS, Ledingham JG: Hyperparathyroidism, platelet intracellular free calcium and hypertension in chronic renal failure. Kidney Int 1993;43:700-705. Vaziri ND: Mechanism of erythropoietin-induced hypertension. Am J Kidney Dis 1999;33:821-828.

Passauer J, Pistrosch F, Büssemaker E, Lässig G, Herbrig K, Gross P: Reduced agonist-induced endotheliumdependent vasodilation in uremia is attributable to an impairment of vascular nitric oxide. J Am Soc Nephrol 2005;16:959-965.

6 Buckalew VM Jr, Berg RL, Wang SR, Porush JG, Rauch S, Schulman G: Prevalence of hypertension in 1,795 subjects with chronic renal disease: the modification of diet in renal disease study baseline cohort. Modification of Diet in Renal Disease Study Group. Am J Kidney Dis 1996;28:811-821.

7 Portaluppi F, Montanari L, Massari M, Di Chiara V, Capanna M: Loss of nocturnal decline of blood pressure in hypertension due to chronic renal failure. Am J Hypertens 1991;4:20-26.

8 Schmieder RE, Messerli FH: Does obesity influence early target organ damage in hypertensive patients? Circulation 1993;87:1482-1488.

-9 Nyamdorj R, Qiao Q, Söderberg S, Pitkäniemi J, Zimmet P, Shaw J, Alberti G, Nan H, Uusitalo U, Pauvaday V, Chitson P, Tuomilehto J: Comparison of body mass index with waist circumference, waist-to-hip ratio, and waist-to-stature ratio as a predictor of hypertension incidence in Mauritius. J Hypertens 2008;26:866-870.

-10 Sarzani R, Salvi F, Dessì-Fulgheri P, Rappelli A: Renin-angiotensin system, natriuretic peptides, obesity, metabolic syndrome, and hypertension: an integrated view in humans. J Hypertens 2008;26:831-843.

-11 Ferris M, Hogan SL, Chin H, Shoham DA, Gipson DS, Gibson K, Yilmaz S, Falk RJ, Jennette JC: Obesity, albuminuria, and urinalysis findings in US young adults from the Add Health Wave III study. Clin J Am Soc Nephrol 2007;2:1207-1214.

12 Elsayed EF, Sarnak MJ, Tighiouart H, Griffith JL, Kurth T, Salem DN, Levey AS, Weiner DE: Waist-to-hip ratio, body mass index, and subsequent kidney disease and death. Am J Kidney Dis 2008;52:29-38.

13 Foster MC, Hwang SJ, Larson MG, Lichtman JH, Parikh NI, Vasan RS, Levy D, Fox CS: Overweight, obesity, and the development of stage 3 CKD: the Framingham Heart Study. Am J Kidney Dis 2008;52:39-48.

14 Kalantar-Zadeh K, Kopple JD, Block G, Humphreys MH: A malnutrition-inflammation score is correlated with morbidity and mortality in maintenance hemodialysis patients. Am J Kidney Dis 2001;38:1251-1263.

15 Pifer TB, McCullough KP, Port FK, Goodkin DA, Maroni BJ, Held PJ, Young EW: Mortality risk in hemodialysis patients and changes in nutritional indicators: DOPPS. Kidney Int 2002;62:2238-2245.

16 Agarwal R: Body mass index-mortality paradox in hemodialysis: can it be explained by blood pressure? Hypertension 2011;58:1014-1020.

17 Woodrow G, Oldroyd B, Turney JH, Davies PS, Day JM, Smith MA: Four-component model of body composition in chronic renal failure comprising dual-energy X-ray absorptiometry and measurement of total body water by deuterium oxide dilution. Clin Sci (Lond) 1996;91:763-769.

$\checkmark 18$ Cha K, Brown EF, Wilmore DW: A new bioelectrical impedance method for measurement of the erythrocyte sedimentation rate. Physiol Meas 1994;15:499-508.

19 Bellizzi V, Scalfi L, Terracciano V, De Nicola L, Minutolo R, Marra M, Guida B, Cianciaruso B, Conte G, Di Iorio BR: Early changes in bioelectrical estimates of body composition in chronic kidney disease. J Am Soc Nephrol 2006;17:1481-1487.

-20 Paniagua R, Ventura MD, Avila-Díaz M, Hinojosa-Heredia H, Méndez-Durán A, Cueto-Manzano A, Cisneros A, Ramos A, Madonia-Juseino C, Belio-Caro F, García-Contreras F, Trinidad-Ramos P, Vázquez R, Ilabaca B, Alcántara G, Amato D: NT-proBNP, fluid volume overload and dialysis modality are independent predictors of mortality in ESRD patients. Nephrol Dial Transplant 2010;25:551-557.

21 Chamney PW, Wabel P, Moissl UM, Müller MJ, Bosy-Westphal A, Korth O, Fuller NJ: A whole-body model to distinguish excess fluid from the hydration of major body tissues. Am J Clin Nutr 2007;85:80-89. 


\section{Kidney \\ Blood Pressure Research}

22 Ohashi Y, Otani T, Tai R, Tanaka Y, Sakai K, Aikawa A: Assessment of body composition using dry mass index and ratio of total body water to estimated volume based on bioelectrical impedance analysis in chronic kidney disease patients. J Ren Nutr DOI: 10.1053/j.jrn.2011.12.006

23 Wabel P, Moissl U, Chamney P, Jirka T, Machek P, Ponce P, Taborsky P, Tetta C, Velasco N, Vlasak J, Zaluska W, Wizemann V: Towards improved cardiovascular management: the necessity of combining blood pressure and fluid overload. Nephrol Dial Transplant 2008;23:2965-2971.

$\checkmark 24$ Watson PE, Watson ID, Batt RD: Total body water volumes for adult males and females estimated from simple anthropometric measurements. Am J Clin Nutr 1980;33:27-39.

-25 Levey AS, Eckardt KU, Tsukamoto Y, Levin A, Coresh J, Rossert J, De Zeeuw D, Hostetter TH, Lameire N, Eknoyan G: Definition and classification of chronic kidney disease: a position statement from Kidney Disease: Improving Global Outcomes (KDIGO). Kidney Int 2005;67:2089-2100.

-26 Matsuo S, Imai E, Horio M, Yasuda Y, Tomita K, Nitta K, Yamagata K, Tomino Y, Yokoyama H, Hishida A: Collaborators developing the Japanese equation for estimated GFR: Revised equations for estimated GFR from serum creatinine in Japan. Am J Kidney Dis 2009;53:982-992.

-27 Pickering TG, Miller NH, Ogedegbe G, Krakoff LR, Artinian NT, Goff D: American Heart Association; American Society of Hypertension; Preventive Cardiovascular Nurses Association: Call to action on use and reimbursement for home blood pressure monitoring: executive summary: a joint scientific statement from the American Heart Association, American Society Of Hypertension, and Preventive Cardiovascular Nurses Association. Hypertension 2008;52:1-9.

-28 Pickering TG: Should we be evaluating blood pressure dipping status in clinical practice? J Clin Hypertens (Greenwich) 2005;7:178-182.

-29 Nicholl DD, Hemmelgarn BR, Turin TC, MacRae JM, Muruve DA, Sola DY, Ahmed SB: Increased urinary protein excretion in the "normal" range is associated with increased renin-angiotensin system activity. Am J Physiol Renal Physiol. 2012;302:F526-F532.

-30 Kimura G, Dohi Y, Fukuda M: Salt sensitivity and circadian rhythm of blood pressure: the keys to connect CKD with cardiovascular events. Hypertens Res 2010;33:515-520.

-31 Davenport A, Hussain Sayed R, Fan S: The effect of racial origin on total body water volume in peritoneal dialysis patient. Clin J Am Soc Nephrol 2011;6:2492-2498.

-32 Cooper BA, Aslani A, Ryan M, Zhu FY, Ibels LS, Allen BJ, Pollock CA: Comparing different methods of assessing body composition in end-stage renal failure. Kidney Int 2000;58:408-416.

-33 Basile C, Vernaglione L, Bellizzi V, Lomonte C, Rubino A, D’Ambrosio N, Di Iorio B: Total body water in health and disease: have anthropometric equations any meaning? Nephrol Dial Transplant 2008;23:1997-2002.

34 Woodrow G, Oldroyd B, Turney JH, Tompkins L, Brownjohn AM, Smith MA: Whole body and regional body composition in patients with chronic renal failure. Nephrol Dial Transplant 1996;11:1613-1618.

35 Woodrow G, Oldroyd B, Turney JH, Davies PS, Day JM, Smith MA: Measurement of total body water by bioelectrical impedance in chronic renal failure. Eur J Clin Nutr 1996;50:676-681. 